\title{
Annealing Effect on Photovoltaic Performance of Hybrid P3HT/In-Situ Grown CdS Nanocrystal Solar Cells
}

\author{
Hung-Chou Liao, ${ }^{\text {a }}$ Naratip Chantarat, ${ }^{a}$ San-Yuan Chen, ${ }^{\text {a,z }}$ Cheng-Hsiung Peng ${ }^{\mathrm{b}}$ \\ ${ }^{a}$ Department of Materials Science and Engineering, National Chiao Tung University, Hsinchu 30010, Taiwan \\ ${ }^{b}$ Department of Materials Science and Engineering, Ming Hsin University of Science and Technology, Hsinfeng, \\ Hsinchu 304, Taiwan
}

\begin{abstract}
The CdS nanocrystals with different aspect ratios (ARs) can be synthesized directly in the presence of conjugated polymer poly(3hexylthiophene-2,5-diyl) (P3HT). The UV-vis spectra of the composite films show a blue shift of the $\pi$ - $\pi^{*}$ transition band with an increasing aspect ratio (AR) of the CdS nanocrystals, which was attributed to the destruction of the ordered structure of polymer chains as supported by PL measurements. Atomic force microscope measurements on P3HT/CdS film also demonstrate the aggregation of CdS nanocrystal in the P3HT matrix is more apparent for the CdS nanocrystals of $\mathrm{AR}=4$ than that of $\mathrm{AR}=16$, indicating a stronger interaction between P3HT and CdS for a larger AR (16), which is favorable for the network structure and formation of percolation paths to increase the transport properties of the P3HT/CdS solar cells. Therefore, a higher power conversion efficiencies (PCE) up to $2.95 \%$ can be obtained for the in-situ-grown $\mathrm{P} 3 \mathrm{HT} / \mathrm{CdS}$ with $\mathrm{AR}=16$ upon annealing treatment at $160^{\circ} \mathrm{C}$ for $60 \mathrm{~min}$.
\end{abstract}

(C) 2011 The Electrochemical Society. [DOI: 10.1149/1.3585668] All rights reserved.

Manuscript submitted January 12, 2011; revised manuscript received March 4, 2011. Published May 2, 2011.

Recently, solar cells based on soluble conjugated polymers have attracted attention because conjugated polymers are promising materials for the development of low-cost optoelectronic devices. ${ }^{1,2}$ Organic photovoltaic cells using conjugated polymer/fullerene blends in a bulk heterojunction architecture have been reported with efficiencies up to $6.5 \%{ }^{3}$ A bulk heterojunction is usually composed of two phases in the photoactive layer: fullerenes or nanocrystals for the acceptor phase and polymers for the donor phase. In a bulk heterojunction, the large interfacial area between the donor and acceptor phases provides sufficient charge separation, which is a prerequisite for solar-cell operation. ${ }^{4}$ Upon irradiation, the conjugated polymer absorbs the photons and produces excitons. Exciton dissociation is known to occur at the interface between two materials with different excited-state energy levels; the electron will move to the lower excited-state energy level of the acceptor because it is energetically favorable. Upon irradiation the electrons from the excitons in the conjugated polymer transfer to the nanocrystals, and the holes from the excitons in the nanocrystals transfer to the conjugated polymer. The optimum overall performance of a bulk heterojunction cell can only be achieved by balancing the various requirements of photogeneration, transport, and extraction of charge carriers.

The bulk heterojunction system still has some difficulty achieving the $10 \%$ power conversion efficiency (PCE) required for commercialization. The most serious problem is the difficulty of controlling the solid-state phase morphology of the two phases in the photoactive layer because the exciton diffusion length in conjugated polymers is typically between 5 and $10 \mathrm{~nm} .{ }^{5,6}$ A variety of ideal photovoltaic structures have been proposed with interdigitated, pure phases spaced by a distance equal to or less than the exciton diffusion length. Some approaches to control donor/acceptor morphology have recently been reported, including the choice of spincoating solvent, ${ }^{7,8}$ slow drying of spin-coated films, ${ }^{9,10}$ and controlled thermal annealing. ${ }^{11,12}$ Among them, thermal annealing is indispensable for complete solvent evaporation and phase separation for the bulk heterojunction formation, and this annealing greatly influences the evolution of the film morphology and device efficiency of hybrid cells in polymer-based systems. ${ }^{13-16}$ For instance, Reyes-Reyes et al. reported that a significant improvement in the power conversion efficiency from 1.1 to $5 \%$ for P3HT-PCBM blends can be obtained by subjecting the sample to thermal annealing, even at low PCBM loading fractions, ${ }^{16}$ because annealing changes not only the film crystallinity but also the aggregation

${ }^{\mathrm{z}}$ E-mail: sanyuanchen@mail.nctu.edu.tw within the PCBM nanophase. However, only a few reports have focused on polymer/inorganic semiconductor composites. Olson et al. reported that phase separation is heavily influenced by nanocrystal ligand choice. ${ }^{17}$ The ligands often dominate the electrical performance of the nanocrystals because they are generally insulators (alkyl chains) that impede charge transport between individual nanocrystals. The ligands can also play an important role in controlling the degree of nanocrystal aggregation, the limitation of which can improve charge transport. ${ }^{18,19}$ Though surface ligands are insulators that prevent charge transport between nanocrystals, surfactants or ligands have been widely used in most literature reports in polymer or polymer/semiconductor hybrid systems. In other words, there are very few reports in the literature in which no ligands were used to control or fabricate composites. An in-situ-growth of the polymer/semiconductor hybrid system could be developed without ligands in order to enhance the performance.

However, the morphology of hybrid cells are strongly influenced by thermal annealing because it is able to change the interaction between the P3HT polymer and the nanoparticles, which will affect the device performance. ${ }^{17,20}$ To effectively employ this ligand-free poly(3-hexylthiophene-2,5-dyl) (P3HT)/CdS nanocrystals with various nanocrystal ARs material system, it is imperative to understand the interaction of P3HT with the CdS nanocrystals and how it affects the blend morphology, phase separation and ultimately the photovoltaic device performance. In this article, the effect of annealing on the physical interaction between P3HT polymer and CdS nanocrystals was investigated on in-situ-grown $\mathrm{CdS}$ nanocrystals with various nanocrystal ARs in the presence of P3HT polymer. The $\mathrm{UV}$-vis results revealed the presence of a strong interaction between the P3HT and the CdS nanocrystals, which would further influence the extent of CdS aggregation in these blend films during the annealing process depending on the AR of CdS nanocrystals. This study on the annealing-condition-dependent PCE reveals that the polymer-nanocrystal interaction has a dramatic effect on the photovoltaic performance of hybrid solar cell devices.

\section{Experimental}

Materials._Cadmium acetate dihydrate (Sigma-Aldrich, analytic grade) and sulfur (Fluka, analytical grade) were the CdS precursors, and dichlorobenzene (DCB, Sigma-Aldrich, anhydrous) and dimethyl sulfoxide (DMSO, Sigma-Aldrich, analytical grade) were the CdS formation solvents. The poly(3-hexylthiophene-2,5-diyl) (P3HT, Sigma-Aldrich) used was electronic grade and regioregular (>98\% head-to-tail). Poly(3,4-ethylene dioxythiophene) doped 
with polystyrenesulfonic acid (PEDOT:PSS, Sigma-Aldrich) was used to smooth the electrode/active layer contact.

CdS-P3HT Synthesis.-The CdS/P3HT composite with the CdS content of $35 \sim 40 \mathrm{wt} \%$ was synthesized by an in-situ method. ${ }^{21}$ The P3HT is acting as a molecular template for geometrical manipulation of CdS nanocrystals. Typically, in a three-neck round-bottom flask equipped with a magnetic stirring bar and condenser, $9 \mathrm{ml}$ of DCB, $3 \mathrm{ml}$ of DMSO, $0.1 \mathrm{~g}$ cadmium acetate dihydrate and $0.01 \mathrm{~g}$ of P3HT were heated to $100^{\circ} \mathrm{C}$ and degassed with nitrogen for 30 min. In a second vial, $0.002 \mathrm{~g}$ of sulfur was dissolved in $1 \mathrm{ml}$ of anhydrous DCB. Both solutions were heated to $180^{\circ} \mathrm{C}$. Then, $1 \mathrm{ml}$ of the sulfur solution was injected swiftly into the P3HT-containing cadmium precursor solution to allow the reaction for $30 \mathrm{~min}$. The mixture solution was purified (to remove any remaining cadmium or sulfur ions and DMSO) by adding anhydrous methanol to form a precipitate. After centrifugation, the supernatant was removed and the composite was dissolved in DCB.

Fabrication and Device Measurement.-Indium tin oxide (ITO)coated glass was purchased from Merck; the resistivity of the glass was $10 \Omega / \mathrm{cm}^{2}$. The ITO-coated glass was precleaned (DI water, acetone, ethanol, and isopropyl alcohol) and treated with oxygen plasma prior to use. The PEDOT:PSS layer $(50 \mathrm{~nm})$ was spin-coated at $2000 \mathrm{rpm}$ and annealed at $120^{\circ} \mathrm{C}$ for $30 \mathrm{~min}$. The $\mathrm{CdS} / \mathrm{P} 3 \mathrm{HT}$ layers $(200 \mathrm{~nm})$ was spin-coated from their corresponding dichlorobenzene solutions $(30 \mathrm{mg} / \mathrm{ml})$ at $1500 \mathrm{rpm}$ and annealed at $150^{\circ} \mathrm{C}$ for $60 \mathrm{~min}$, followed by thermal evaporation of an aluminum electrode. Aluminum top electrodes $(100 \mathrm{~nm})$ were deposited by thermal evaporation through a shadow mask, resulting in individual devices with a $0.1 \mathrm{~cm}^{2}$ nominal area. Power efficiency measurements were performed under AM1.5G conditions $\left(100 \mathrm{~mW} / \mathrm{cm}^{2}\right)$. J-V characteristics were measured using a Keithley 2400 source meter. The reported efficiencies are obtained from an average value of four measurements from a set of four regions on each substrate.

Structural and Optical Properties Analysis.- To investigate the nanostructure of the CdS-P3HT composites, transmission electron microscopy (TEM; JEOL, JEM-2100F, Field Emission Transmission Electron Microscope) was employed. The optical properties were analyzed by UV-vis spectroscopy and a fluorescence spectrometer (Hitachi F4500) equipped with a $450 \mathrm{~nm}$ excitation source. All of the films were drop-cast and care was taken to ensure identical processing. The pristine P3HT film was made from a solution that underwent the same processing steps (without adding cadmium acetate and sulfur) with the same polymer concentration. ${ }^{1}$ HNMR spectra of the blend solutions were recorded using a VARIAN 500 $\mathrm{MHz}$. Chemical shifts are referenced to tetramethylsilane for ${ }^{1} \mathrm{H}$. All NMR spectra measurements were done in $\mathrm{CDCl}_{3}$ at room temperature.

Thermal Properties Analysis.-Differential scanning calorimetry (DSC) curves for P3HT and the two different P3HT/CdS nanorod composites were obtained with a TAQ2000 DSC. Approximately 4 $\mathrm{mg}$ of each sample were loaded in an aluminum pan. The analyses were conducted from -10 to $230^{\circ} \mathrm{C}$ at heating and cooling rates of $20^{\circ} \mathrm{C} / \mathrm{min}$ and a nitrogen flow rate of $5 \mathrm{ml} / \mathrm{min}$.

\section{Results and Discussion}

Figures $1 \mathrm{a}$ and $1 \mathrm{~b}$ show the transmission electron microscopy (TEM) images of P3HT/CdS composites with CdS nanocrystals of $\mathrm{AR}=4$ and 16, respectively. The average aspect ratio (AR) of the CdS nanocrystals was measured by TEM and estimated from ten nanocrystals. The TEM image of a single nanorod is illustrated in the inset of Fig. 1b. The P3HT/CdS nanocomposites with CdS nanocrystals of $A R=4$ and 16 were synthesized by an in-situ growth via $\mathrm{P} 3 \mathrm{HT}$ conducting polymer where the P3HT is acting as a molecular template for geometrical manipulation of CdS nanocrystals and in the meantime, as an efficient electron conductor in composite form.
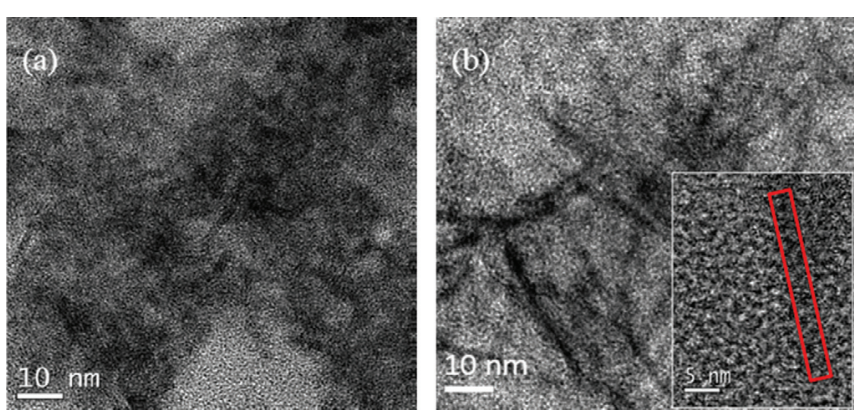

Figure 1. (Color online) TEM images of P3HT/CdS composites with (a) $\mathrm{AR}=4$ and (b) $\mathrm{AR}=16$. The inset: high resolution TEM image of the lattice plane of a single CdS nanorod.

Through such a templating process, CdS nanorods with various aspect ratios can be easily manufactured via a co-solvent DCB-toDMSO system, where the solvency of the co-solvent mixture is believed to control the conformational variation of the P3HT chain. The in-situ growth mechanism of high-aspect-ratio CdS nanocrystal can be referred to our previous study. ${ }^{21}$ After adding cadmium acetate in the P3HT solution, an intermolecular interaction probably resulted from a strong dipole-dipole or ion-dipole interaction between the $\mathrm{Cd}^{2+}$ ions and $\mathrm{S}$ atoms, prevailing along the backbone of the P3HT chain. The planar P3HT conformation may provide flat, stacking molecular architecture. As such, the $\mathrm{Cd}^{2+}$ ions may be immobilized in a confined space within the network structure of the P3HT through the dipole-dipole interaction and stayed in place while subjected to a subsequent nucleation-and-growth process with the adding sulfur ions. This would result in uniformly and randomly distributed CdS nanorods within the polymer. Therefore, the singlecrystalline nature of the nanorods of various aspect ratios may suggest an epitaxial-like growth of the CdS nanocrystals along the exposed sulfur-bearing segments of a given macromolecular chain in a given solvent environment. Such a scenario, if molecularly accessible, can be applicable for the nanorods of technically desirable aspect ratio through the manipulation of co-solvent environment where the conformational development of the P3HT polymer can be possible. In other words, an extended and straightened, e.g., in a linear form of, P3HT chain can be evolved if a "good" solvent is applied upon the synthesis of the nanorod. Therefore, the aspect ratio of the resulting nanorod can be controlled according to the length scale of the P3HT chain that extended into the diluting environment. On this basis, a variation of the DCB-to-DMSO volume ratio from $7: 5,8: 4$ to $9: 3$ gave the nanorods of aspect ratio increasing from 4,8 to 16 for the samples with the same concentration under similar reaction conditions, respectively. Figure $2 \mathrm{a}$ shows the UV-Vis absorption spectra for the thin films of P3HT and the P3HT/CdS composites with various ARs as spun cast on glass substrates. For the pure P3HT film, the solid-state absorption spectra showed two peaks at 521 and $556 \mathrm{~nm}$ and one shoulder at $605 \mathrm{~nm}$. The shoulder at $605 \mathrm{~nm}$ is generally attributed to a higher crystallization or ordering of intra-chain interactions in semiconducting polymers and the peak intensity depends on the order degree in the intermolecular chains of the microcrystalline domains. ${ }^{12,22}$ These bands can be attributed to the $\pi-\pi^{*}$ transition. ${ }^{22}$ As the AR of CdS nanocrystal increases, the absorption bands are blue-shifted. The shift of $\pi-\pi^{*}$ transition absorption peaks to shorter wavelength indicates an increasing density of conformational defects, which causes the loss of conjugation. ${ }^{23}$ This indicates that the blue shifts are due to the insitu growth of CdS nanocrystals in the P3HT matrix, which induced the consequent destruction of the $\mathrm{P} 3 \mathrm{HT}$ chain ordering during solvent evaporation. Figures $2 \mathrm{~b}$ and $2 \mathrm{c}$ show the UV-vis spectra measured for P3HT/CdS (AR $=4$ and 16) films before and after annealing at different temperatures for $60 \mathrm{~min}$. After thermal annealing, the spectra shifted towards longer wavelengths and the shoulder at $610 \mathrm{~nm}$ became more distinguishable when the 

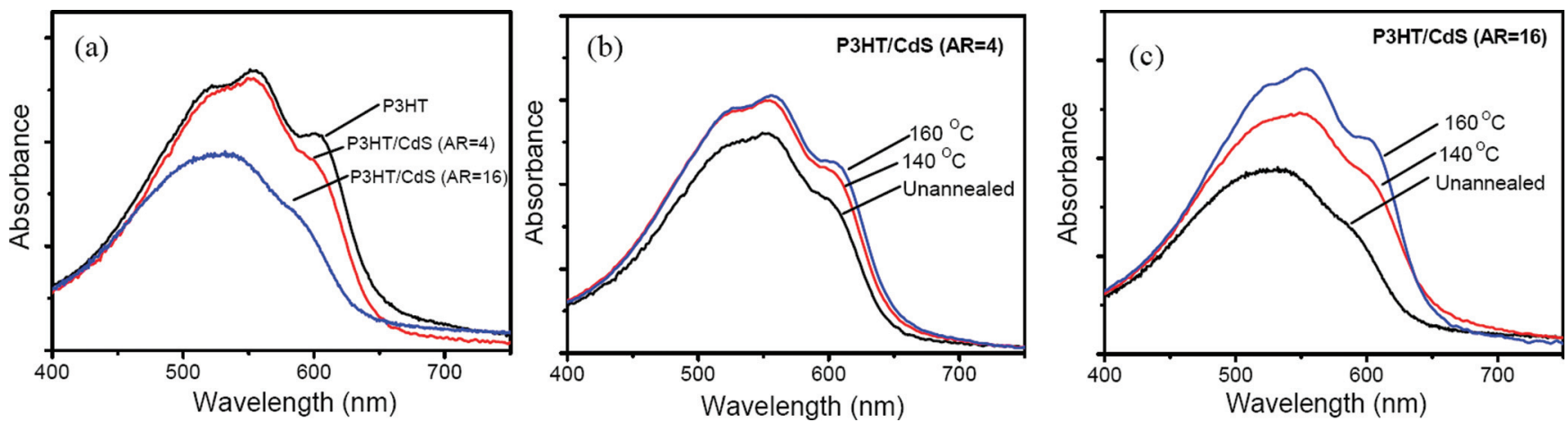

Figure 2. (Color online) (a) UV-Vis absorption spectra obtained for P3HT/CdS thin films with various ARs. UV-Vis absorption spectra of P3HT/CdS thin films with AR of (b) 4 and (c) 16 before and after annealing treatments.

annealing temperature increased because the interchain interaction between P3HT chains is stronger. ${ }^{22}$ It is implied that the annealing treatments can improve ordering of P3HT chains.

The PL spectra in Fig. 3 display the same trend, which supports this understanding of the structural variation of the P3HT/CdS composite film after annealing treatment. The theoretical energy level diagram was also illustrated in inset of Fig. 3. The electrons generated at the lowest unoccupied molecular orbital (LUMO) level of P3HT $(-3.0 \mathrm{eV})$ can be transferred to the conduction band of CdS $(-4.0 \mathrm{eV})$. The PL intensity of the annealed sample was higher than that of the as-grown (or unannealed) samples. This indicates that upon annealing, the photo-induced electron transfer from the P3HT to CdS becomes less efficient. The increase of the PL intensity on thermal annealing is correlated with the interaction of the $\mathrm{P} 3 \mathrm{HT} / \mathrm{CdS}$ to increase the size or number of P3HT crystallites with dimensions larger than the exciton diffusion length, allowing for radiative relaxation rather than electron transfer at surrounding heterojunctions. Because the concentration of the CdS nanocrystals in the film does not change upon annealing, the change of the photoluminescence intensity should primarily originate from the CdS aggregation and the morphology evolution of the active layer. A larger increase in PL intensity was found for the P3HT/CdS composites with an AR of 4 (from line 1 to 3) than those with an AR of 16 (from line 4 to 6 ), which indicates that upon annealing, the photoinduced electron transfer from the P3HT to $\mathrm{CdS}$ for the $\mathrm{CdS}$ nanocrystals of $\mathrm{AR}=4$ becomes less efficient than that with $\mathrm{CdS}$ nanocrystals of $\mathrm{AR}=16$. Furthermore, the PL spectra of P3HT showed resolved vibronic structures at around 647 and $708 \mathrm{~nm}$ and

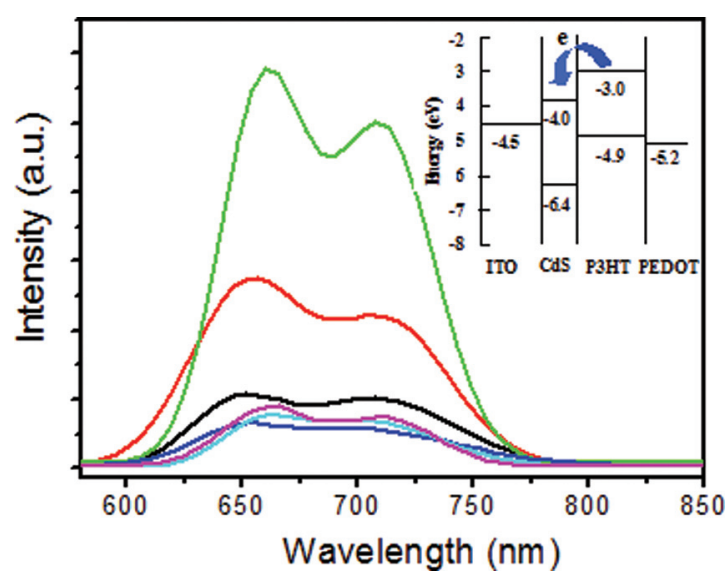

Figure 3. (Color online) The fluorescence spectra of P3HT/CdS nanocrystals with an $\mathrm{AR}$ of 4 and 16 before and after heat treatment. Line (1): $\mathrm{AR}=4$, unannealed. Line (2): $\mathrm{AR}=4,140^{\circ} \mathrm{C}$. Line (3): $\mathrm{AR}=4,160^{\circ} \mathrm{C}$. Line (4): $\mathrm{AR}=16$, unannealed. Line (5): $\mathrm{AR}=16,140^{\circ} \mathrm{C}$. Line (6): $\mathrm{AR}=16,160^{\circ} \mathrm{C}$. The inset: energy diagram of P3HT/CdS photovoltaic device. found that Gaussian curves fit the PL curve well. The data of the Gaussian-fitting of the two peaks are shown in Table I. The PL emission peak located at $\sim 647 \mathrm{~nm}(1.92 \mathrm{eV})$ was assigned to the pure electronic transition $(0-0$ transition) and the peak at $\sim 708 \mathrm{~nm}$ $(1.75 \mathrm{eV})$ was assigned to the first vibronic band $(0-1$ transition). ${ }^{24,25}$ The red shifts in PL emission after annealing treatment suggest that the polymer chains are $\pi$-stacked on each other. ${ }^{26,27}$ The increase of the conformational order in the composites was attributed to the alignment of the polymer chains in the vicinity of nanocrystals during annealing treatments.

Figure 4 shows the differential scanning calorimetry (DSC) thermograms of pure $\mathrm{P} 3 \mathrm{HT}$ and the $\mathrm{P} 3 \mathrm{HT} / \mathrm{CdS}$ nanocrystal composites. An exothermic peak showing the typical features of a melting transition was detected for all the samples. The melting temperature of the P3HT/CdS nanocrystal composites depends on the crystallization conditions. The DSC data show that the exothermic peak was shifted to a lower temperature for the $\mathrm{P} 3 \mathrm{HT} / \mathrm{CdS}$ composites as compared to the pure $\mathrm{P} 3 \mathrm{HT}$, which is clear evidence of the influence of the CdS nanocrystals on the thermal properties. The shifting of the P3HT melting peak to a lower temperature indicates that the semi-crystalline nature of P3HT is partially hindered by CdS nanocrystals. We believe that the decrease in the crystallinity of the $\mathrm{P} 3 \mathrm{HT} / \mathrm{CdS}$ nanocrystal composites is related to the fact that the insitu-grown CdS nanocrystals embedded between the P3HT chains inhibit the main-chain crystallization due to the strong interaction between the CdS nanocrystals and the P3HT. ${ }^{28}$ Furthermore, it is noted that the $\mathrm{P} 3 \mathrm{HT} / \mathrm{CdS}$ nanocrystal composite with an $\mathrm{AR}=16$ shows a larger shift than that with an AR of 4. This indicates that the degree of order in the P3HT is further reduced when the CdS of $\mathrm{AR}=16$ is used. This observation, along with UV-vis absorption and PL measurements, indicates that on annealing, the growth of ordered polymer domains is more hindered by $\mathrm{P} 3 \mathrm{HT} / \mathrm{CdS}$ composites with an AR of 16. These differences from thermal annealing effects are important in the determination of the morphology of the device active layers and the improvement of the photovoltaic performance of P3HT/CdS composite-based solar cells.

It is well known that the performances of photoactive layers based on P3HT/nanocrystal blends are usually enhanced when a

Table I. PL measurement of the P3HT/CdS nanocrystals with different ARs.

\begin{tabular}{cccc} 
& $\begin{array}{c}\text { Annealing } \\
\text { temperature }\left({ }^{\circ} \mathrm{C}\right)\end{array}$ & $\begin{array}{c}0-0 \text { transition } \\
(\mathrm{nm})\end{array}$ & $\begin{array}{c}0-1 \text { transition } \\
(\mathrm{nm})\end{array}$ \\
\hline $\mathrm{AR}=4$ & non & 647.6 & 708.7 \\
& 140 & 651.5 & 713.6 \\
$\mathrm{AR}=16$ & 160 & 658.8 & 713.7 \\
& non & 645.7 & 700.2 \\
& 140 & 657.5 & 706.4 \\
& 160 & 659.7 & 711.9
\end{tabular}




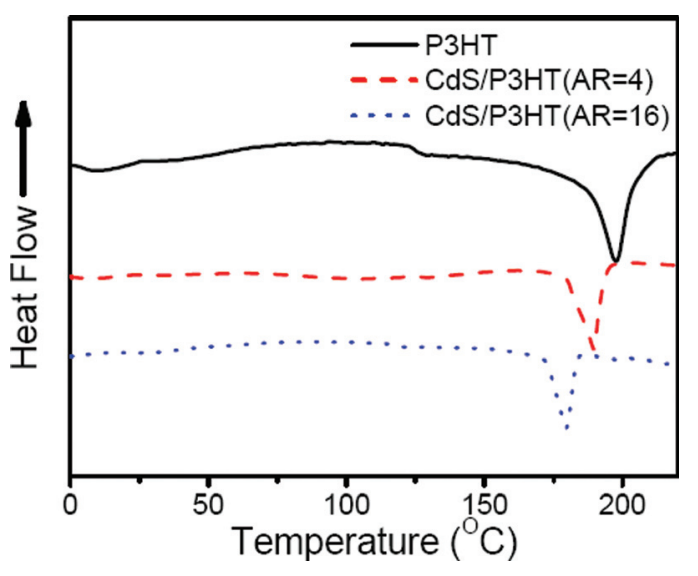

Figure 4. (Color online) DSC thermograms of pure P3HT and P3HT/CdS nanocrystals with an $\mathrm{AR}$ of 4 and 16 at a heating rate of $20^{\circ} \mathrm{C} / \mathrm{min}$.

thermal-annealing step is applied. Therefore, an optimization concerning the annealing temperature and duration was carried out for $\mathrm{P} 3 \mathrm{HT} / \mathrm{CdS}$ nanocrystals with an $\mathrm{AR}=4$ and 16. As shown in Fig. 5, the device using the nanocrystals with an $\mathrm{AR}=16$ shows a higher power conversion efficiency (PCE) as compared to that with an AR of 4 at different annealing conditions. Generally, for the photoactive layers consisting of equiaxial nanocrystals, electron transport is dominated by hopping. In contrast, for the photoactive layers consisting of elongated nanocrystals, the band conduction is prevalent in the P3HT/CdS composites ${ }^{29}$ because nanorods with a high AR can penetrate through a large portion of the device to develop percolation pathways for electron transport. In other words, longer nanocrystals more easily form a percolation path between two electrodes, which makes more contribution to photovoltaic conversion.

In addition, the improved device performance depends heavily on the annealing conditions, as clearly seen in Fig. 5. The devices annealed at $160^{\circ} \mathrm{C}$ show the best performance, with efficiency as high as $1.5 \%(\mathrm{t}=40 \mathrm{~min})$ and $2.9 \%(\mathrm{t}=60 \mathrm{~min})$ for $\mathrm{AR}=4$ and 16 , respectively. This improvement is primarily attributed to the higher photon absorption and better crystallinity of the P3HT chains, as evidenced by the UV-vis spectra (Fig. 2). However, as increasing the annealing temperature over $160^{\circ} \mathrm{C}$, it results in performance degradation, which can be explained by morphological changes and low structural stability at high temperatures.

Figure 6 shows the surface morphology change as monitored by AFM. The morphology can be further investigated for the origin of the long-term stability of P3HT/CdS devices with different annealing temperatures. For the as-deposited (unannealed) film with $\mathrm{AR}=4$ and 16 , the surface is very smooth: the root mean square (rms) roughnesses are 1.067 and $1.184 \mathrm{~nm}$, respectively. However, after thermal treatment at $160^{\circ} \mathrm{C}$, the rms roughness obtained from Figs. $6 \mathrm{c}$ and $6 \mathrm{~d}$ for $\mathrm{AR}=4$ and 16 become 7.259 and $4.821 \mathrm{~nm}$, respectively, because the CdS nanocrystals aggregate during thermal (a)

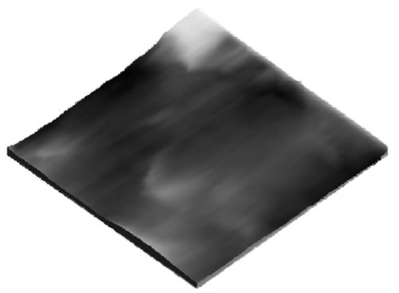

(b)
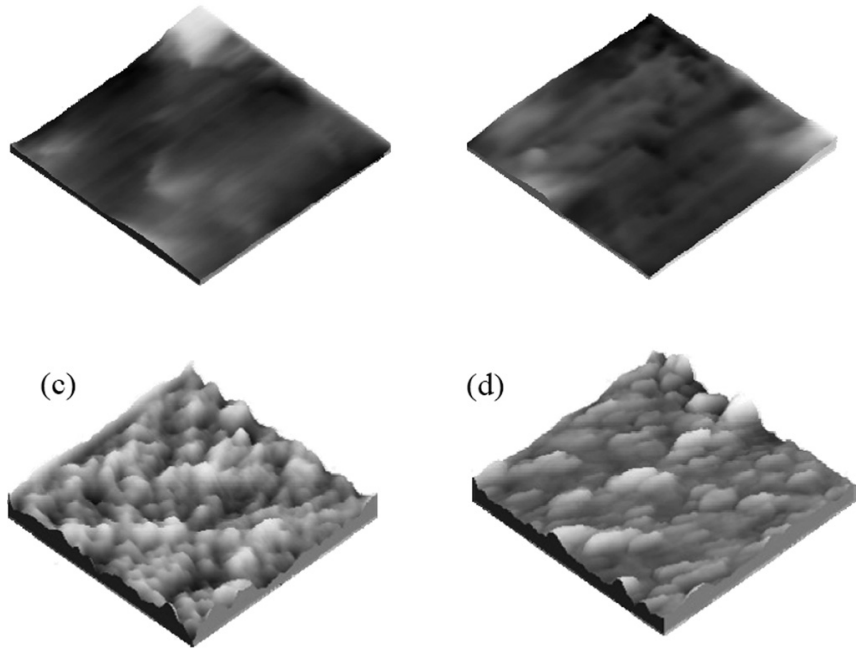

Figure 6. $5 \mu \mathrm{m} \times 5 \mu \mathrm{m}$ AFM height images of P3HT/CdS films with (a) $\mathrm{AR}=4$ and (b) $\mathrm{AR}=16$. (c) $\mathrm{AR}=4$ and (d) $\mathrm{AR}=16$ annealed at $160^{\circ} \mathrm{C}$ for $60 \mathrm{~min}$. Height scale: (a), (b) $10 \mathrm{~nm}$ and (c), (d) $90 \mathrm{~nm}$.

annealing. Moreover, it can be found that the scale of the aggregations for $\mathrm{AR}=4$ is larger than that for $\mathrm{AR}=16$, indicating that the $\mathrm{CdS}$ nanocrystals of $\mathrm{AR}=4$ aggregate more easily than those of $\mathrm{AR}=16$, which leads to the reduced charge segregation and device performance in the film of $\mathrm{AR}=4 .^{30,31}$

To understand the interaction and molecular structure between $\mathrm{P} 3 \mathrm{HT}$ and CdS nanocrystals during in-situ growth of P3HT/CdS, ${ }^{1} \mathrm{H}$ NMR measurements were performed on the pristine P3HT and $\mathrm{P} 3 \mathrm{HT} / \mathrm{CdS}$ nanocrystals composites with an AR of 4 and 16. As compared to pure P3HT in Figs. 7a-7c show that the broader proton peaks at a chemical shift of $\sim 6.98$ [thiophene ring (a)] and $\sim 2.79$ ppm [hexyl chain (b)] were clearly observed for P3HT/CdS, which confirms the interaction between the polymer and the CdS. Additionally, the proton peaks from the hexyl chain $(\mathrm{e})(\sim 0.91 \mathrm{ppm})$ was only slightly broadened compared with the proton peaks from the thiophene ring (a) and hexyl chain (b). A similar phenomenon has been also reported for polymer-CNT composites; the interactions of polymers with CNTs cause broadening and reduced intensity of ${ }^{1} \mathrm{H}$ NMR peaks. ${ }^{32,33}$ This indicates that the thiophene ring is much closer to the CdS surface than the hexyl chain. This conclusion was further supported by the change of the relative intensity of proton peaks (a), (b), and (e). In the pristine P3HT solution, the ratio of protons (a), (b), and (e) is almost 1:2:3, whereas in $\mathrm{P} 3 \mathrm{HT} / \mathrm{CdS}$, this ratio is $0.94: 1.89: 3.0$ and $0.85: 1.73: 3.0$ for $\mathrm{AR}=4$ and 16 , respectively. As a result, a stronger adsorption between CdS nanoparticles and $\mathrm{P} 3 \mathrm{HT}$ takes place at $\mathrm{AR}=16$. This explains the observations made earlier on the basis of absorption and DSC spectra, which causes the change in the morphology and the PCE.
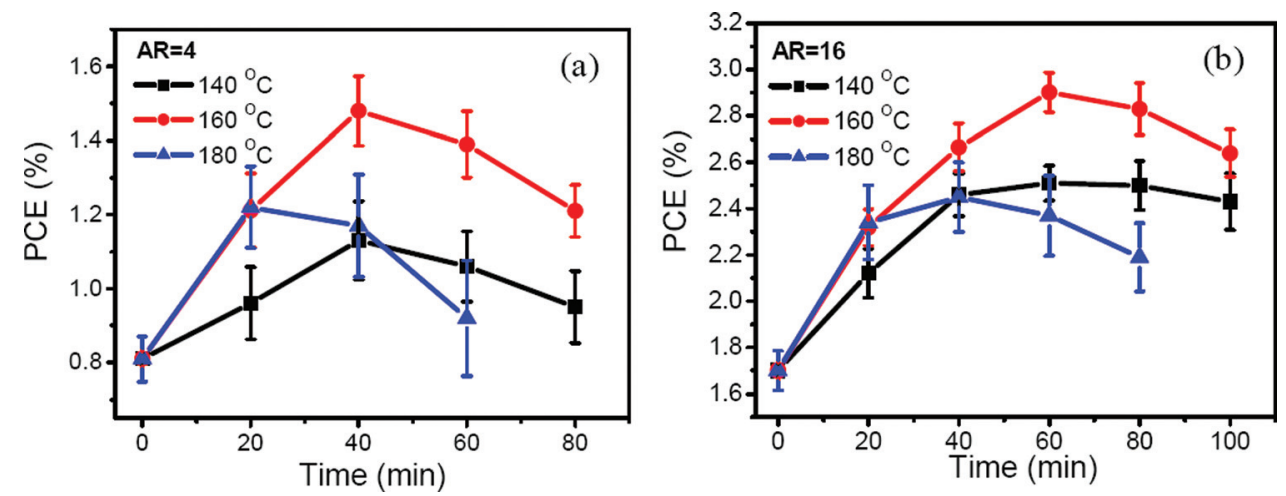

Figure 5. (Color online) Power conversion efficiency plotted as a function of annealing temperature and time for $\mathrm{P} 3 \mathrm{HT} /$ $\mathrm{CdS}$ composites with (a) $\mathrm{AR}=4$ and (b) $\mathrm{AR}=16$. 


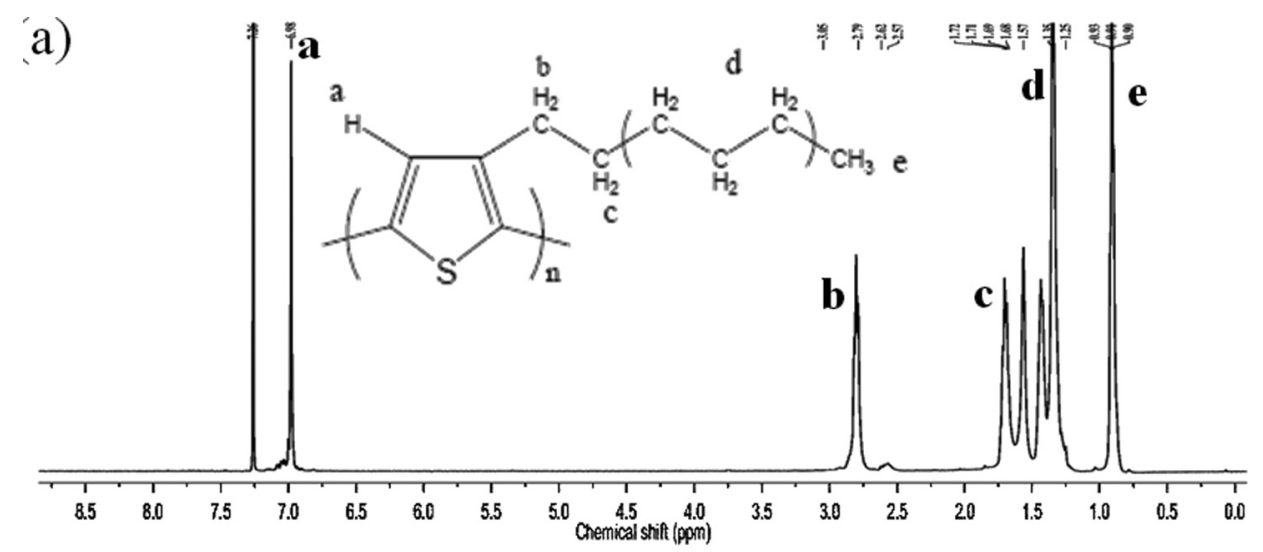

(b)

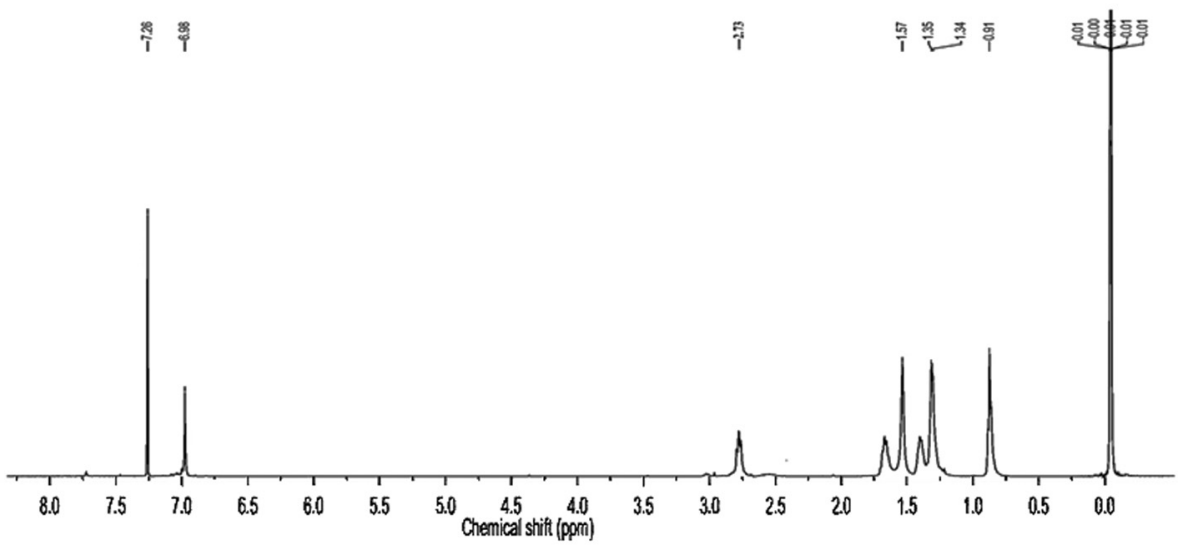

Figure 7. ${ }^{1} \mathrm{H}$ NMR spectra for (a) P3HT and $\mathrm{P} 3 \mathrm{HT} / \mathrm{CdS}$ composites with the AR of (b) 4 and (c) 16 .

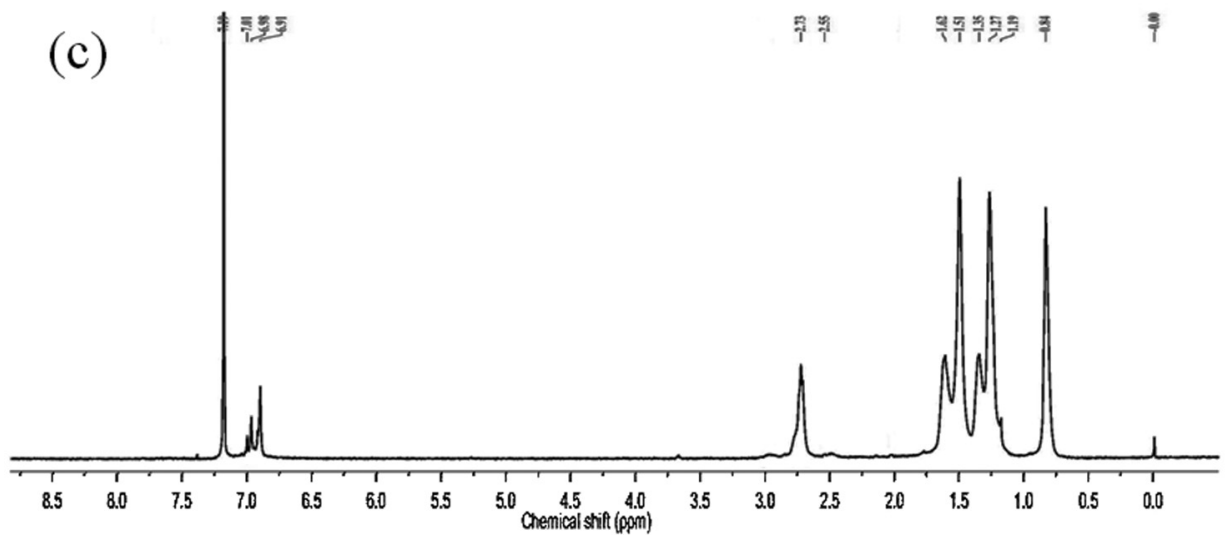

In conclusion, we prepared $\mathrm{P} 3 \mathrm{HT} / \mathrm{CdS}$ nanocrystal composites with different ARs by the in-situ growing process. ${ }^{1} \mathrm{H}$ NMR analysis indicates physical attachment between the CdS nanocrystals and the thiophene ring of P3HT. The interaction strength between the P3HT and $\mathrm{CdS}$ surface increases with the AR, indicating a stronger interaction between P3HT and CdS for a larger AR (16), which is favorable for the network structure and formation of percolation paths to increase the transport properties of the $\mathrm{P} 3 \mathrm{HT} / \mathrm{CdS}$ solar cells. As a result, the $\mathrm{P} 3 \mathrm{HT} / \mathrm{CdS}$ composite with elongated $\mathrm{CdS}$ nanocrystals of $\mathrm{AR}=16$ made a large contribution to the improvement in PCE up to $2.95 \%$ compared to that with $\mathrm{CdS}$ of $\mathrm{AR}=4$ upon annealing at $160^{\circ} \mathrm{C}$ for $60 \mathrm{~min}$.

\section{Acknowledgment}

This work was financially supported by the National Science Council of the Republic of China, Taiwan under Contract No. NSC98-3114-E-009-006.

\section{References}

1. C. J. Brabec, Sol. Energy Mater. Sol. Cells, 83, 273 (2004).

2. J. M. Kroon, S. C. Veenstra, L. H. Slooff, W. J. H Verhees, M. M. Koetse, J. Sweelssen, H. F. M. Schoo, W. J. E. Beek, M. M. Wienk, R. A. J. Janssen, et al., in 20th European Photovoltaic Solar Energy Conference and Exhibition, Barcelona, Spain, June 6-10, 2005.

3. J. Y. Kim, K. Lee, N. E. Coates, D. Moses, T. Nguyen, M. Dante, and A. J. Heeger, Science, 317, 222 (2007).

4. G. Yu, J. Gao, J. C. Hummelen, F. Wudl, and A. J. Heeger, Science, 270, 1789 (1995).

5. D. E. Markov, E. Amsterdam, P. W. M. Blom, A. B. Sieval, and J. C. J. Hummelen, J. Phys. Chem. A, 109, 5266 (2005)

6. J. J. M. Halls, K. Pichler, R. H. Friend, S. C. Moratti, and A. B. Holmes, Appl. Phys. Lett., 68, 3120 (1996).

7. G. Li, V. Shrotriya, J. Huang, Y. Yao, T. Moriarty, K. Emery, and Y. Yang, Nature Mater., 4, 86 (2005)

8. V. D. Mihailetchi, H. Xie, B. Boer, L. M. Popescu, J. C. Hummelen, P. W. M. Blom, and L. J. A. Koster, Appl. Phys. Lett., 89, 012107 (2006).

9. S. E. Shaheen, C. J. Brabec, N. S. Sariciftci, F. Padinger, T. Fromherz, and J. C. Hummelen, Appl. Phys. Lett., 78, 841 (2001). 
10. Y. Kim, S. A. Choulis, J. Nelson, D. D. C. Bradley, S. Cook, and J. R. Durrant, Appl. Phys. Lett., 86, 063502 (2005).

11. H. Hoppe and N. S. Sariciftci, J. Mater. Chem, 16, 45 (2006).

12. U. Farva, M. A. Khan, and C. Park, 2008 33rd IEEE Photovoltaic Specialists Conference, Fraunhofer Institute for Solar Energy Systems, p. 1731 (2008).

13. T. Ahn and H. L. Sein-HoHa, Appl. Phys. Lett., 80, 392 (2002).

14. T. Erb, U. Zhokhavets, G. Gobsch, S. Raleva, B. Stuhn, P. Schilinsky, Ch. Waldauf, and Ch. J. Brabec, Adv. Funct. Mater., 15, 1193 (2005).

15. P. Sonar, K.P. Sreenivasan, T. Madddanimath, and K. Vijayamohanan, Mater. Res. Bull., 41, 198 (2006).

16. M. Reyes-Reyes, K. Kim, and D. L. Carroll, Appl. Phys. Lett., 87, 083506 (2005).

17. J. D. Olson, G. P. Gray, and S. A. Carter, Sol. Energy Mater. Sol. Cells, 93, 519 (2009).

18. G. Kalyuzhny and R. W. Murray, J. Phys. Chem. B, 109, 7012 (2005).

19. W. U. Huynh, J. J. Dittmer, W. C. Libby, G. L. Whiting, and A. P. Alivisatos, $A d v$. Funct. Mater., 13, 73 (2003)

20. L. H. Nguyen, H. Hoppe, T. Erb, S. Gunes, G. Gobsch, and N. S. Sariciftci, $A d v$ Funct Mater., 171071 (2007).

21. H. C. Liao, S. Y. Chen, and D. M. Liu, Macromolecules, 42, 6558 (2009).

22. P. J. Brown, D. S. Thomas, A. Köhler, J. S. Wilson, J.-S. Kim, C. M. Ramsdale, H. Sirringhaus, and R. H. Friend, Phys. Rev. B, 67, 064203 (2003).
23. O. Inganas, W. R. Salaneck, J. E. Osterholm, and J. Laakso, Synth. Met., 22, 395 (1988).

24. M. Sharma, D. Kaushik, R. R. Singh, and R. K. Pandey, J. Mater. Sci.: Mater. Electron., 17, 537 (2006)

25. P J. Brown, D. S. Thomas, A. Köhler, J. S. Wilson, J.-S. Kim, C. M. Ramsdale, H. Sirringhaus, and R. H. Friend, Phys. Rev. B, 67, 064203 (2005).

26. L. Li, C. M. Chan, K. L. Yeung, J. X. Li, K. M. Ng, and Y. Lei, Macromolecules, 34, 316 (2001).

27. H. Yang, T. Shin, J. L. Yang, K. Cho, C. Y. Ryu, and Z. Bao, Adv. Funct. Mater. 15, 671 (2005)

28. L. Mandelkern, Crystallization of Polymers, McGraw-Hill, New York (1964).

29. W. Huynh, J. Dittmer, and A. P. Alivisatos, Science, 295, 2425 (2002).

30. S. Miyanishi, K. Tajima, and K. Hashimoto, Macromolecules, 42, 1610 (2009).

31. A. Swinnen, I. Haeldermans, M. vande Ven, J. D'Haen, G. Vanhoyland, S. Aresu, M. D'Olieslaeger, and J. Manca, Adv. Funct. Mater., 16, 760 (2006).

32. A. Star, J. F. Stoddart, D. Steuerman, M. Diehl, A. Boukai, E. W. Wong, X Yang, S. W. Chung, H. Choi, and J. R. Heath, Angew. Chem. Int. Ed, 40, 1721 (2001).

33. J. Chen, H. Liu, W. A. Weimer, M. D. Halls, D. H. Waldeck, and G. C. Walker, $J$ Am. Chem. Soc., 124, 9034 (2002). 